See Article page XXX.

\section{Commentary: The radial artery: An influential partner for the 2 internal thoracic arteries}

\author{
James Tatoulis, AM, MBBS, MS, MD, FRACS, \\ FRCST, FCSANZ
}

Irrespective of how coronary artery bypass graft surgery (CABG) is performed, there are 3 fundamental arterial grafting strategies; that is, the use of 1,2 , or 3 or more arterial grafts. Questions arise: Are 2 arterial grafts better than 1? Are 3 arterial grafts (or total arterial revascularization) better than 2? If so, is bilateral internal thoracic artery (BITA) and radial artery (RA) (ie, BITA + RA) a worthwhile and superior strategy to BITA and saphenous vein graft(s) (SVG) (ie, BITA + SVG)?

Multiple large observational studies and meta-analyses over the past 20 years have reported superior long-term prognosis for 2 arterial grafts over 1, without compromising perioperative mortality and morbidity, ${ }^{1}$ even in older patients. $^{2}$

Recently, the as-treated analysis of the Arterial Revascularization Trial, ${ }^{3}$ and the meta-analysis of all the randomized controlled trials of RA versus SVG as a second graft, ${ }^{4}$ have confirmed the superiority of 2 arterial grafts over 1 . Further, there is evidence that 3 arterial grafts may be better than $2,{ }^{5}$ and others have reported benefits of total arterial revascularization over lesser degrees of multiarterial grafting. ${ }^{6}$ Conversely, there has not been a report that 1 arterial graft is better than 2, nor that 2 are better than 3 .

\footnotetext{
From the Department of Cardiothoracic Surgery, Royal Melbourne Hospital, Melbourne, Victoria, Australia; and Department of Surgery, University of Melbourne, Melbourne, Victoria, Australia.

Disclosures: The author reported no conflicts of interest.

The Journal policy requires editors and reviewers to disclose conflicts of interest and to decline handling or reviewing manuscripts for which they may have a conflict of interest. The editors and reviewers of this article have no conflicts of interest.

Received for publication July 13, 2021; revisions received July 13, 2021; accepted for publication July 13, 2021.

Address for reprints: James Tatoulis, AM, MBBS, MS, MD, FRACS, FRCST, FCSANZ, Department of Cardiothoracic Surgery, Royal Melbourne Hospital, Medical Centre, 300 Grattan St, Suite 28, Parkville, Melbourne, VIC, Australia 3050 (E-mail: james.tatoulis@mh.org.au).

J Thorac Cardiovasc Surg 2021; $\mathbf{\square}: 1-2$

$0022-5223 / \$ 36.00$

Copyright (c) 2021 by The American Association for Thoracic Surgery

https://doi.org/10.1016/j.jtcvs.2021.07.019
}

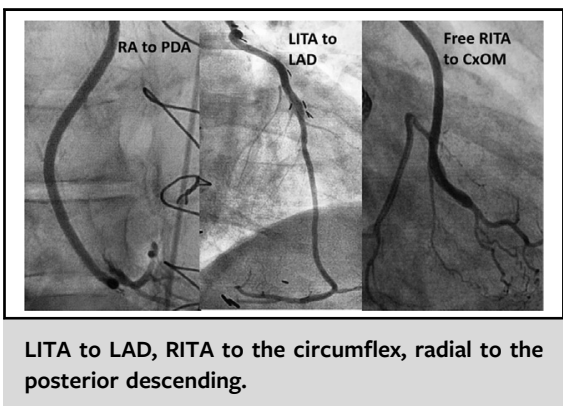

CENTRAL MESSAGE

The addition of a radial artery graft to a bilateral internal thoracic artery strategy enhances long-term survival and is especially relevant for younger patients undergoing CABG.

The meta-analysis by Formica and colleagues ${ }^{7}$ explores the accumulated data as to whether 3 arterial grafts, specifically BITA + RA trump BITA + SVG. Whilst this addresses only a small subset of patients, considering only $4 \%$ to $20 \%$ of patients receive BITA in the first place, ${ }^{7}$ let alone 3 arterial grafts, it is an important contribution to our knowledge, and potential incorporation into CABG practice, especially in younger patients. The methodology undertaken by Formica and colleagues ${ }^{7}$ is sound, the numbers (2500 matched patients) robust, and the inferences valid. Assuming the 2 ITAs are used to the 2 most important arteries and territories - usually on the left-hand side - it is reasonable to consider an RA as a third arterial conduit, provided care is taken to ensure hand blood supply, appropriate RA size, quality, spasm prophylaxis, and avoidance of competitive flow.

The RA should not be used indiscriminately, especially to the right coronary artery; for example, in situations such as a nondominant right coronary artery, stenosis $<80 \%$, and prior extensive infarction in the targeted area. In such situations, grafting may not even be required, nor beneficial, or even be detrimental. Deploying an RA to an already infarcted area may make no prognostic difference and be inappropriate, a waste of a valuable conduit, of time, and an unnecessary harvest and intervention.

In contradistinction, placing an RA to a large, tightly stenosed posterior descending artery that supplies preserved ischemic inferior wall and inferior septum myocardium would be intuitively beneficial, potentially improving cardiac performance, avoiding a future inferior infarct, 
regional wall dysfunction, and type III B ischemic mitral regurgitation. Current operative techniques, whether on or off pump, and optimal myocardial protection allows CABG to be performed with $<1 \%$ perioperative mortality and minimal morbidity irrespective of the surgical strategy and number of arterial conduits used. ${ }^{1-7}$ Hence it is important for cardiac surgeons to focus on the long-term outcomes.

In this meta-analysis, the average patient age at surgery was 60 years. The potential life span of this cohort in many communities is an additional 20 to 25 years. Hence, any strategy that improves survival, especially if it is relatively morbidity-free, is welcome.

The important findings by Formica and colleagues ${ }^{7}$ are that even with BITA, adding an RA resulted in 3 more patients being alive at 10 years and 5 more alive at 15 years for every 100 undergoing operation. A very worthwhile result, especially because the operative time would be the same because the left RA can be harvested simultaneously with the left ITA, or the right RA harvested concurrently with the right ITA.

In coronary practice, if a patient is to undergo BITA and needs a further graft to a tightly stenosed significant artery supplying a substantial amount of viable myocardium, then an RA may be the optimal choice given that it will enhance long-term survival as reported by this analysis.
Formica and colleagues ${ }^{7}$ provide further evidence to support multiarterial grafting with a BITA + RA strategy. Although a $5 \%$ difference between $83 \%$ and $78 \%$ survival at 15 years may sound minor, it means that 5 more humans will be alive-an important outcome for those individuals and their families.

\section{References}

1. Takagi H, Goto SN, Watanabe T, Mizuno Y, Kauai N, Umemoto T. A meta-analysis of adjusted hazard ratios from 20 observational studies of bilateral versus single internal thoracic artery coronary artery bypass grafting. $J$ Thorac Cardiovasc Surg. 2014;148:1282-90.

2. Navia D, Espinoza J, Vrancic N, Piccinini F, Camporrotondo M, Dorsa A, et al. Bilateral internal thoracic artery grafting in elderly patients: any benefit in survival? J Thorac Cardiovasc Surg. October 3, 2020 [Epub ahead of print].

3. Taggart DP, Gaudino MF, Gerry S, Gray A, Lees B, Dimagli A, et al. Effect of total arterial grafting in the arterial revascularization trial. J Thorac Cardiovasc Surg. March 19, 2020 [Epub ahead of print].

4. Gaudino M, Benedetto U, Fremes S, Ballman K, Biondi-Zoccai G, Sedrakyan A, et al. Association of radial artery graft vs saphenous vein graft with long-term cardiovascular outcomes among patients undergoing coronary artery bypass grafting a systematic review and meta-analysis. JAMA. 2020;324:179-87.

5. Gaudino M, Puskas JD, Di Franco A, Ohmes RB, Iannaccone M, Barbero U. 3 arterial grafts improve late survival: a meta-analysis of propensity matched studies. Circulation. 2017;135:1036-44.

6. Tatoulis J, Wynne R, Skillington PD, Buxton BF. Total arterial revascularization: achievable and prognostically effective. A multicentre analysis. Ann Thorac Surg. 2015;100:1268-75.

7. Formica F, Maestri F, D’Alessandro S, Di Mauro M, Singh G, Gallingani A, et al. Survival impact of radial artery usage in addition to bilateral internal thoracic arterial grafting: a meta-analysis. J Thorac Cardiovasc Surg. 2021. XXX:XXX. 